This is an electronic reprint of the original article. This reprint may differ from the original in pagination and typographic detail.

Author(s): Koskinen, Satu; Lämsä, Anna-Maija

Title: Development of trust in the CEO-chair relationship

Year: $\quad 2017$

Version:

Please cite the original version:

Koskinen, S., \& Lämsä, A.-M. (2017). Development of trust in the CEO-chair relationship. Baltic Journal of Management, 12(3), 274-291.

https://doi.org/10.1108/BJM-02-2017-0029

All material supplied via JYX is protected by copyright and other intellectual property rights, and duplication or sale of all or part of any of the repository collections is not permitted, except that material may be duplicated by you for your research use or educational purposes in electronic or print form. You must obtain permission for any other use. Electronic or print copies may not be offered, whether for sale or otherwise to anyone who is not an authorised user. 


\title{
Development of trust in the CEO-Chair relationship
}

\begin{abstract}
Purpose: This study explores trust development in the dyadic relationship of CEO and Chair of the Board.

Approach: A narrative approach is adopted to examine the meanings that CEOs and Chairpersons give to trust in their relationship, and to explore trust as an evolving phenomenon that can increase or decline over the course of the relationship. The data include 16 CEO-Chair dyads from Finnish limited companies.
\end{abstract}

Findings: The results suggest that trust may exist on different levels and evolve in various ways during the course of the relationship. Integrity and agreement on company strategy are proposed to form the foundation for trust in the CEO-Chair relationship, whereas ability and benevolence are necessary for trust to develop to a higher level.

Research limitations: Studying trust development based on data generated at one point of time and in only one country are the major limitations of the study.

Practical implications: It is proposed that the level of trust influences value creation in the relationship.

Originality/value: The study adds to the limited number of previous studies on the CEOChair relationship and contributes to the literature on trust development by making visible the viewpoint of both partners, and the meaning of the different components of trust.

Key words: Chief Executive Officer (CEO), Chairperson of the Board (Chair), Interpersonal trust, Trust development, Narrative research 


\section{Introduction}

A working relationship between the CEO and Chair of the Board has been proposed as necessary for effective governance and pivotal to the performance of the Board (Roberts, 2002; Kakabadse et al., 2006), and to be at the heart of many other key organisational relationships (Roberts and Stiles, 1999). Trust, too, has been increasingly recognised as a central mechanism within organisational relations and governance, and the significance of trust has been highlighted in the literature of the CEO-Chair relationship (e.g. Roberts and Stiles, 1999; Roberts, 2002; Kakabadse et al., 2010; Koskinen and Lämsä, 2016).

This study explores trust development in the CEO-Chair relationship from both partners' viewpoints. An empirical study based on data from 16 Finnish CEO-Chair dyads is conducted. Despite the noted importance of the CEO-Chair relationship in the corporate governance system, academic research on this relationship in general and trust in particular has been rare. In addition to access difficulties (Pettigrew, 1992), a significant reason for the relatively small amount of previous research is probably the dominant governance model in the US, namely CEO duality. In this model, the CEO and Chair are one and the same person, and the antecedents and consequences of CEO duality, rather than the CEO-Chair relationship, have been the focus of research (Krause et al., 2014). Still, for example in many European countries, these roles are more typically separated and held by two persons (Huse, 2007). Drawing on stewardship theory, it can be said that the steward, such as a CEO, can be trusted to try to achieve the objectives of the organisation, and that the steward's and principals' interests are aligned (Davis et al., 1997).

Following a social constructionist viewpoint (Berger and Luckmann, 1966), the focus in this study is on the social process of relationship building (Uhl-Bien, 2006), rather than on the $\mathrm{CEO}$ and Chair as individuals. In the social constructionist perspective, the notion of trust as a fixed or static phenomenon is questioned; instead, trust and its development are understood as fluid and many-faceted, and shaped by context (Wright and Ehnert, 2010).

We use narrative methodology to focus on the topic. One benefit of the methodology is that the stories that the CEO and Chair tell about their relationship give us the opportunity to understand the meanings that they give to trust, and to examine the events and issues that may have contributed to the current level of trust in the relationship (Gergen and Gergen, 1988; 
Riessman, 2008). A narrative approach allows us to explore trust as a dynamic phenomenon that can increase or decline over the course of the relationship, and consequently we can bring out the plurality and processual characteristics of trust development in the CEO-Chair relationship (Polkinghorne, 1995; Rhodes and Brown, 2005). This narrative study takes narrative to be a textual account of a sequence of events (Polkinghorne, 1988; Gergen and Gergen, 2006; Riessman, 2008) concerning trust in the relationship as experienced and recounted by the CEO and Chair. An advantage of the narrative approach is that it provides an opportunity to overcome the limitations of time by enabling people to transfer their experiences from one time to another, and to create storylines in which they deal with issues under discussion (Ricoeur, 1983).

The present explorative study makes three main contributions to the subject. Firstly, the study contributes to the literature on trust development by exploring the evolving dimension of the relationship (Gabrielsson and Huse, 2002) and the meaning of the three main components of trust, i.e. ability, benevolence and integrity (Mayer et al., 1995), to trust development. We challenge the idea of trust development as a single, progressive, stage-by-stage process, as suggested in earlier research (e.g. Lewicki and Bunker, 1996; Lämsä and Pucetaite, 2006) and meet a general call for studies on trust (e.g. Lewicki et al., 2006) that look more at the dynamics and development of trust. Secondly, we contribute to the literature on interpersonal trust by making visible the viewpoint of both partners. Even if the reciprocal nature of trust in supervisor-subordinate relationships has been acknowledged before (e.g. Whitener et al., 1998; Serva et al., 2005; Seppälä et al., 2011), trust has rarely been studied as a dyadic phenomenon from the viewpoint of both parties (Yakovleva et al., 2010; Nienaber et al., 2015). Thirdly, by increasing knowledge on trust development in the CEO-Chair relationship, we contribute to the stream of research that aims to enhance understanding of the processual dynamics and human side of corporate governance and Board work (e.g. Huse et al., 2005; Roberts et al., 2005; Huse, 2007; Bailey and Peck, 2013).

\section{Theoretical framework}

Trust development in dyadic, organisational relationships

In this study, trust is examined as an interpersonal (e.g. Whitener et al., 1998) phenomenon, with the focus on a specific dyadic relationship. We adopt an integrative model and the definition of trust proposed by Mayer et al. (1995 p. 712), applicable to a relationship with a 
specific, identifiable party, as 'the willingness of a party to be vulnerable to the actions of another party based on the expectation that the other will perform a particular action important to the trustor, irrespective of the ability to monitor or control that other party'. According to Mayer et al. (1995 p. 717-719), there are three main components that contribute to dyadic trust: ability (a group of skills, competencies and characteristics that enable a party to have influence within some specific domain), benevolence (the extent to which a trustee is believed to want to do good to the trustor), and integrity (the trustor's perception that the trustee adheres to a set of principles that the trustor finds acceptable).

The model of trust put forward by Mayer et al. (1995) includes a feedback loop, and trust is understood as dynamic and constantly changing. The trustor evaluates the outcomes of previous vulnerability and makes new assessments of the ability, benevolence and integrity of the dyadic partner as the relationship develops. The propensity to trust, i.e. a trustor's general willingness to trust others, is a stable trait that influences the level of trust, particularly in the beginning of the relationship. The trustor's interpretation of the context, such as the level of risk, influences both their evaluation of trustworthiness and the need for trust (Mayer et al., 1995). However, the model does not examine the development of mutual trust as a reciprocal phenomenon. Still, empirical studies on trust-building in the superior-subordinate relationship have proposed that it is a reciprocal, complementary process (e.g. Serva et al., 2005) in which the supervisor's trust is shown by giving autonomy to the subordinate, which further promotes trust in the supervisor (Seppälä et al., 2011), trust appearing to be 'both a requirement for and an outcome of the process' (Atkinson, 2004 p. 581).

All the three components have been found to be highly correlated with trust and to have significant, unique relationships with trust (Colquitt et al., 2007). The relative importance of the three characteristics has been argued to vary according to the context (Serva and Fuller, 2004; Colquitt et al., 2011), with greater subordinate vulnerability increasing the importance of the perceived leader integrity or ability, rather than benevolence (Lapidot et al., 2007). Benevolence and integrity have been proposed to be more relationship-based than ability, which is more task-specific and based on objective markers, such as education and experience (Serva and Fuller, 2004; Yakovleva et al., 2010). Moreover, it has been suggested that behaviours reflecting leader ability and integrity are more salient in incidents of trust erosion, while the perceived benevolence of the leader is more salient in trust-building (Lapidot et al., 2007). 
Trust in the CEO-Chair and the CEO-Board relationship

The dyadic CEO-Chair relationship has some specific characteristics not found in typical superior-subordinate relationships that can be assumed to be meaningful from the perspective of trust. Firstly, earlier research on trust in supervisor-subordinate relationships has assumed that information asymmetry works in the supervisor's favour (e.g. Schoorman et al., 2007; Nienaber et al., 2015), but in carrying out their duties, Chairpersons (and the whole Board) are largely dependent on the information provided by the CEO (e.g. Hooghiemstra and Van Manen, 2004; Bailey and Peck, 2013; Koskinen and Lämsä, 2016). This dependence can be assumed to increase vulnerability from the Chair's point of view and can therefore be significant from the perspective of trust. Secondly, previous research (e.g. Stewart, 1991; Roberts and Stiles, 1999; Roberts, 2002) has proposed a strong interdependence between the CEO and Chair. Thirdly, it has been proposed that even if it is the duty of the Board as a collective to supervise the CEO, in practice the Chair forms a closer working relationship with the CEO than do the rest of the Board. For example, the Chair will work with the CEO to prepare for Board meetings and will discuss emerging problems and opportunities with the CEO outside Board meetings (e.g. Roberts, 2002; Koskinen and Lämsä, 2016).

It has been suggested that the independence of non-executive directors, such as the Chair, enhances the control task, whereas the task of service requires proximity and a trusting relationship with the CEO (e.g. Westphal, 1999; Zhang, 2013). Del Brio et al. (2013) argued that a Board Director's perceptions of the ability, integrity and benevolence of the CEO have different effects on their conduct in terms of resource provision and monitoring. Del Brio et al. (2013) found that positive perceptions of the CEO's integrity and benevolence are associated with greater provision of resources, that positive perceptions of integrity lead to lower levels of monitoring, and that high perceptions of CEO ability lead to lower levels of resource provision, and that monitoring is only reduced when the perceived ability of the CEO reaches a very high level. It has been proposed that the dynamics of trust development between the Board and the CEO may come about in a cycle that reinforces itself and is selffulfilling. A control-oriented management approach is more likely to produce agency relationships, whereas a more trusting approach may result in stewardship relationships (Davis et al., 1997; Sundaramurthy and Lewis, 2003). 
Trust has been acknowledged as necessary to open information sharing and mutual learning (Huse et al., 2005), which further facilitate shared conceptions of reality in the CEO-Chair relationship (Kakabadse et al., 2010). For the non-executive Chair in particular, the CEO is a vital source of information in company matters, and trust has been proposed to be both necessary to and built through dyadic communication (Roberts, 2002; Koskinen and Lämsä, 2016). Roberts and Stiles (1999) suggest a virtuous circle of relationship building in the CEOChair relationship, highlighting the significance of the dynamic of interaction during the early months of the relationship for trust-building. If trust does not develop in the relationship, the partners easily remain at a considerable distance from each other, which may lead to misunderstandings and to a vicious, rather than virtuous circle (ibid). It has been suggested that the CEO's initiative for open information sharing on emerging issues is pivotal for the development of trust in the relationship, although it requires that the CEO trusts that her/his action space will not be threatened as a result (Koskinen and Lämsä, 2016). Additionally, in order to be open in the relationship, the CEO needs to trust that the Chair is not a rival CEO (Roberts, 2002).

\section{Finland as a context of the study}

The context of the empirical study is Finland. According to the Limited Liability Companies Act of Finland (Osakeyhtiölaki, 624, 2006), the purpose of a company is to generate profits for its shareholders. The Board of Directors is responsible for the administration of the company, the appropriate organisation of the company's operations, the appropriate arrangements for controlling the company's accounts and finances, and the appointment and dismissal of the CEO. It is the Chairperson's duty to see that the Board meets when necessary. The CEO is responsible for the executive management of the company as instructed and ordered by the Board, and for supplying the Board with the information it needs for the performance of its duties. CEO duality is allowed by the Companies Act, but separating the roles of $\mathrm{CEO}$ and Chair is in accordance with the recommendations of the Finnish Corporate Governance Code for listed companies (Arvopaperimarkkinayhdistys ry, 2010). According to the Code, the CEO cannot be a member of the nomination committee that may be established to prepare the election of the Board of Directors.

Lämsä and Pucetaite (2006) argue that the socio-cultural context influences the process of trust development. Finland is a high-trust society, and ranks among the highest in the world 
(e.g. Bjørnskov, 2007) in cross-country comparisons measuring generalised trust (for example, by the numbers answering yes to the question 'In general, do you think that most people can be trusted?).

\section{Methodology}

Data production

A narrative research approach with open-ended, in-depth (Eriksson and Kovalainen, 2008) interviews conducted separately with both the CEO and the Chair from the same company was applied. This form of interview was chosen because the very limited previous knowledge on the topic indicates that a flexible, explorative approach will best enable respondents to bring out their experiences of the most important relevant issues. In line with several authors (Polkinghorne, 1995; Rhodes and Brown, 2005; Heikkinen et al., 2014) we define a narrative as a contextual account of a sequence of events that have happened to people over time. Additionally, a narrative is a story of the events and viewpoints told by a person as she/he understood and experienced them.

Purposeful sampling (Eriksson and Kovalainen, 2008) was utilised in the selection of the sample of various, information-rich cases for the interviews. The selection criteria of the dyads were formed on the basis of factors that can be assumed, from prior research on Boards, to influence the CEO-Chair relationship (see Huse, 2007). The primary selection criteria included ownership type and size of the company, as well as the length of the CEO-Chair relationship. In addition, gender and personal ownership of the CEO and Chair in the company were taken into account to ensure a diverse sample. Based on the criteria, 18 dyads from Finnish listed and non-listed companies were asked to join the study, two of which refused. The resulting sample of 16 dyads included a total of 31 respondents, as one respondent was interviewed in two capacities: as the CEO of one company and the Chair of another. In 11 dyads, the CEO was in office before the Chair. All dyads had worked together at least one year before the interview. None of the companies was solely owned by one or both of the dyadic partners. The main characteristics of the sample are presented in Table 1.

Table 1. The sample of respondents 


\begin{tabular}{|c|c|c|c|c|}
\hline & $\begin{array}{c}\text { Listed } \\
\text { company }\end{array}$ & $\begin{array}{c}\text { Family- } \\
\text { owned }\end{array}$ & $\begin{array}{c}\text { Other type of } \\
\text { ownership }\end{array}$ & Total \\
\hline$<\mathbf{2 0 0}$ employees & 0 & 2 & 3 & $\mathbf{5}$ \\
\hline $\mathbf{2 0 0 - 1 0 0 0}$ employees & 1 & 1 & 3 & $\mathbf{5}$ \\
\hline$>\mathbf{1 0 0 0}$ employees & 4 & 1 & 1 & $\mathbf{6}$ \\
\hline Total number of companies & $\mathbf{5}$ & $\mathbf{4}$ & $\mathbf{7}$ & \\
\hline & & & & $\mathbf{1 6}$ \\
\hline Relationship length & $\mathbf{1 - 2}$ years & $\mathbf{2 - 5}$ years & $>\mathbf{5}$ years & \\
\hline Total number of dyads & 5 & 4 & 7 & \\
\hline & & & & \\
\hline & Men & Women & Major ownership & \\
\hline Chairpersons & 14 & 2 & 3 & $\mathbf{3 2}$ \\
\hline CEOs & 14 & 2 & 3 & \\
\hline Total number of interviews & $\mathbf{2 8}$ & $\mathbf{4}$ & & \\
\hline
\end{tabular}

Specific attention in conducting the research was paid to building trust with the respondents. The pre-information sent to the respondents included information about the purpose of the study, the professional background of the interviewing author, and the narrative, open-ended style of the interview. The respondents were also informed that the study was supported by a network of Finnish Board Directors, and the contact details of a well-known member of the network were included. Both in the pre-information e-mails and at the start of the interview, it was described very clearly that the interview would be anonymous and also confidential in regard to the dyadic partner, and the respondents were encouraged to openly narrate their experiences.

The interviews opened with a question about the respondent's route to their current position as the CEO or Chair and about the start of the relationship, i.e. when and how the partners had first met, and how the co-operation had started to evolve. More questions focusing specifically on trust and about the concrete issues and events that had impacted the level of trust in the relationship (Gergen and Gergen, 1988) were asked during the interview, depending on what the respondents had already said. For example, if a CEO said she/he knew that she/he could trust the Chair not to interfere in a way she/he would disapprove of, she/he was asked about events that had contributed to that knowledge. A typical interview lasted around 90 minutes, and the interviews were recorded and transcribed verbatim. 


\section{Data analysis}

In the analysis, the narrative framework suggested by Gergen and Gergen (1988) was followed. According to them, when narrating their experiences, respondents express a valued outcome and the story line becomes more positive when the outcome is positive, such as a high-trust relationship, and more negative if the outcome is a disappointment or a failure. In order to keep the story line coherent, respondents select which events from the whole experience to narrate (Bruner, 1991; Polkinghorne, 1995). From the viewpoint of trust development between the CEO and Chair, this means that if they experience the current trust of their relationship as being on a high level, they will narrate events that have contributed to this end, whereas if they perceive current trust to be on a lower level than previously, they will talk about events that have eroded their trust in the relationship.

According to Gergen and Gergen (1988), all plots of narratives take a progressive, regressive or stable form as regards their evaluative shifts over time. Building on these basic forms, more variations in story lines, such as tragedy, comedy, romance or happily-ever-after can be identified (Gergen and Gergen, 1988): the tragedy narrative is about a rapid downfall; in the comedy narrative, challenges or problems precede a progressive narrative and a happy end; the romance narrative consists of many progressive and regressive phases; and in a happilyever-after narrative, the progressive narration is followed by a stable, positive end.

Following the framework of Gergen and Gergen (1988), the transcribed interview materials were read many times in order to identify the story line, events in the course of the story line, and the current level of trust in the relationship. The whole story of the relationship, as narrated by the respondents, rather than only those events or phrases in which trust was specifically mentioned, was included in the analysis. As a result of the process of interpretation we formed four groups of narratives of trust development in the CEO-Chairman relationship: The successful development of trust; A stable, adequate level of trust; Differing views, diverging directions; and The Chair's ability as a promoter of trust. They will be presented next.

\section{Results}

The successful development of trust 
In eight dyads both partners constructed a positive, progressive story line, i.e. of strongly developing or developed trust. Four of these dyads, which had worked together for less than three years, were still on a progressive phase and expected the good, steady progress to continue in the future, whereas another four dyads, all of which had worked together for more than three years, constructed a more stable, high level of trust, i.e. the story line of happilyever-after (Gergen and Gergen, 1988). In three dyads, the CEO had been the first of the partners in the position, and in three companies, the Chair was a major owner in the company. Four of the dyads had known each other well before the current relationship from other workrelated settings, and this was narrated as having enhanced trust development in the relationship.

The relative importance of ability and benevolence for trust development was narrated differently depending on the partners' order of entry into the relationship. When the Chair had been the first in position, she/he had been in charge of the CEO's recruitment process and trust had already started to develop during that process, i.e. before the CEO took office. The partners described their dyadic co-operation at the start of the relationship as intensive, with the Chair providing strong support and advice to the new CEO. Moreover, the intensive start was narrated as having enabled the partners to establish a common view on company strategy relatively early on, forming a solid base for the further development of their dyadic cooperation and trust.

The CEO's transparency and initiative in co-operation were described as particularly important for the development of trust early in her/his tenure, when she/he had not yet been able to display her/his ability to achieve results and execute strategy in the current position. As described by a CEO who had been in the role for $1 \frac{1}{2}$ years at the time of the interview: 'For sure, transparency is the most important thing. I have tried to enhance transparency myself, of course. It means that I tell as openly as possible what's going on, what is going to be done, and what kind of problems we've had.' However, both partners underlined that in addition to the CEO's transparency, her/his ability to execute strategy and deliver the promised results is necessary for trust. In addition to constantly evaluating the financial results, Chairpersons also evaluated action and named various events and actions of the CEO that had enhanced their perception of the CEO's ability, particularly early on in the CEO's tenure. These included showing the ability to learn fast, finding an excellent, innovative solution to a sudden business problem on a factory site, successfully developing customer 
relationships and the competence of the management team, handling a media crisis well, and renewing the ethical code of conduct in the company. One Chair described the development of trust with the new CEO as follows: 'For sure, trust is earned through actions. I mean results, actions, open information. And also, in my opinion, trust increases when you allow more freedom, and can still see that the information stays at the same level as before.'

Even if the CEOs said that they had particularly appreciated the Chairperson's support and advice at the very start of the relationship, they had begun to expect to get more autonomy as soon as they had been able to show ability to perform in line with the Board's expectations. The willingness of the Chair to give the CEO autonomy had been and still was an important sign of trust, and something that in return encouraged the CEO's openness with the Chair. And as the above quote of a Chair reveals, the CEO's openness despite increased freedom reciprocally increased the Chairperson's trust. The dyadic partners also narrated that existing trust had further increased in challenging situations the partners had faced together, such as major strategic changes and acquisitions.

Within the two dyads in which the CEO had been the first in the position and the dyadic partners had not worked together in other contexts, the dynamics of trust development were narrated differently from what has been described above. Within these dyads, the CEO had already been able to prove her/his ability, whereas the new Chair had had very limited knowledge of the business and had been very dependent on the CEO's information-sharing in order to build her/his company-specific knowledge. However, the CEO narrated that at an early stage in the relationship she/he had faced a severe challenge and opposition in the Boardroom, and the Chair had strongly supported her/him and had been able to settle the disagreement in the CEO's favour. This occasion, along with some other early positive experiences, had resulted in the CEO's enhanced perception of the Chairperson's benevolence and ability to support them. The CEO described how this had encouraged her/him to systematically enhance the Chair's company-specific knowledge by very open information sharing and continuous strategic discussions, and the resulting frequent interaction had strongly and reciprocally developed dyadic trust and a shared view on company strategy.

In sum, the development of trust was narrated in this group as a story of continuous success without any major issues that had eroded trust in the relationship. A high trust relationship was characterised by high levels of perceived ability and benevolence on both sides, by open, reciprocal communication, largely initiated by the $\mathrm{CEO}$, and a resulting deep understanding of 
the partner's way of thinking, by jointly constructed interpretations in changing situations, and by a shared, commonly negotiated view of company strategy. Integrity, on the other hand, was mentioned as a necessity, but not as a developing element of trust, and all dyads said that they shared a similar set of values.

\section{A stable, adequate level of trust}

There were three dyads in this group, and they had worked together for more than four years. The CEO had been in position for several years, and longer than the Chair. None of the respondents was a major owner in the company.

The respondents narrated a relatively stable, non-developing story line and said that trust had been preserved rather than developed during the relationship. One CEO described this as follows: 'Maybe the starting point is rather to trust people and not to suspect. And if there was any betrayal, only then would it erode. And in our case, trust was there in the beginning, and it has remained.' Even if the Chairpersons spoke of some events that had reduced their trust in the CEO's openness, such as late information about business and personnel problems or key executive nominations, they downplayed the significance of these events compared with the good financial performance the CEO was able to achieve, and they did not question the CEO's honesty. However, the Chair admitted recognising that the CEO was not as open as she/he could be, as described by a Chair: 'Well, (the CEO's first name) obviously is not the most open CEO. But I can't really say that she/he has hidden any problems either.' The quality of the relationship and the level of trust were constructed as adequate, 'good enough', but not as good as the respondents thought would be possible or fully satisfactory.

The CEO's ability was the dominant driver for trust, as during her/his long tenure the CEO had been able to perform strongly in terms of both financial results and the strategic development of the company. Rather than seeking support or advice from the Chair, the CEO underlined her/his own responsibilities and position in the company's driver's seat, and said that there had rarely been any need to contact the Chair over any emerging issues. The reason for this was that it would be time-consuming and inefficient, as the CEO and her/his team had the best knowledge and competence to solve any problems as they arose. The CEO highlighted that autonomy was her/his main driver and therefore the Chair's willingness not to interfere was a key issue as regards the CEO's trust in the Chair. However, the CEO said that the ability of the Board, including the Chair, to contribute to the business and challenge 
the CEO was not as good as she/he thought it could be, and that she/he should be challenged more in the Boardroom.

The Chair, partly based on her/his own experience as a CEO, narrated understanding of the CEO's need for autonomy, and said that as the financial and strategic performance of the company were on such a good level, she/he had not seen any need to interfere more; the Chair considered that interfering too much would not do any good, but would rather cause problems in the relationship.

To conclude, in this group, trust was largely based on the CEO's ability and the Chair's benevolence, but as the interaction of the partners was infrequent on account of the relatively low level of benevolence of the CEO in terms of openness, the company-specific ability of the Chair and dyadic trust had not developed to a higher level. The dyadic partners said that they agreed on company strategy, but highlighted the role of the CEO and her/his team in strategy creation and development, rather than dyadic co-operation.

\section{Differing views, diverging directions}

In this group with two dyads, the CEO had been the first of the partners in the role and the duration of the relationship was less than four years. None of the respondents was a major owner in the company. The respondents narrated a significantly lower level of dyadic trust than they would have liked, and the story lines were different between the partners. In one dyad, the story line of one partner was largely stable but optimistic about the future, whereas the other partner constructed the regressive story line of a tragedy and said that she/he had decided to leave her/his position because of the problems in the relationship. In the other dyad, one partner constructed a low-trust story line with some erosion of trust during the course of the relationship, whereas the other partner's story line was mostly, even if only slightly, progressive and optimistic. The experienced or expected progress of the two respondents was reported as being based on the development of the other partner's ability when they got more experience in their position.

For the CEO, the starting point of the relationship had been a disappointment. The CEO had started in the position with another Chair, whose skill and support she/he had greatly appreciated, and the CEO had not had the same perception of the background and competence of the current Chair fitting the needs of the company and her/himself. The CEO believed that her/his own ability was better and more relevant than the Chairperson's, but also admitted that 
she/he felt lonely in the position without the Chairperson's support and challenge. The CEO narrated that the Chair did not understand the company's business and current situation in the same way as the CEO did and that the dyadic partners had had differing views on priorities. Due to these differences, the CEO narrated experiencing the Chairperson's guidance as irrelevant, complicating, and as preventing or at least slowing down her/his work on more important issues. The CEO said she/he had rarely taken the initiative to contact the Chair, and the dyadic interaction was described as mostly taking place in formal, pre-planned meetings initiated by the Chair. The lack of positive feedback from the Chair in general and on one particular occasion on which another Board Director had raised a positive issue was mentioned as having eroded the CEO's trust in the Chairperson's benevolence.

The Chair narrated that she/he had recognised the CEO's lack of confidence in her/his competence right from the start of the relationship. However, her/his view was also that the CEO's competence had not been and still was not fully satisfactory, particularly as regards her/his skill in strategically developing the company to ensure long-term success, and the Chair talked about differing on how to develop company strategy and urgency with which it should be done. Still, the Chair expressed appreciation of the CEO's ability to run the day-today operations of the company, although she/he also saw room for improvement in the company's current performance.

The Chair construed poor communication and a lack of dialogue between the partners as frequently leading to misunderstandings between them. In particular, the CEO's lack of initiative in giving the Chair information was narrated as having prevented the development of trust in the relationship, as highlighted in the following comment from a Chair: 'I cannot say that she/he is untrustworthy. But then, dialogue with other people is the weakness. She/he doesn't bother to inform me of most issues. That means that I have to go and drag out information from her/him bit by bit.' Moreover, the Chair had experienced some unpleasant surprises that had eroded her/his trust in the CEO, for example when the CEO did not inform the Board until very late in the day about the costs of a major project that had significantly exceeded its budget, or when the Chair found out that some organisational developments had not progressed as she/he had assumed.

Despite the unsatisfactory level of trust, the respondents constructed trust, rather than distrust, between them. For example, one CEO commented as follows: 'Anyway, there is trust, too, in our relationship. If I think, for example, about whether I'd get support from the Chair in a 
tight situation, I still think that I would. I mean, it is not that bad, anyway.' Moreover, the respondents said that despite the evident problems in the relationship, they had no reason to question the honesty or ethical conduct of the dyadic partner, and described the behaviour of the partners in the relationship as 'correct'.

In sum, the relationship was characterised by a negative dynamic, in which the partners did not have enough trust in the benevolence and ability of the other partner. This resulted in a need on the part of the Chair to guide the CEO, and a lack of initiative and openness on the part of the CEO when trying to avoid the Chair's guidance. This led the partners at a distance from each other, and they had few opportunities to discuss and create common interpretations of changing situations and the possible responses to them. This caused yet further misunderstandings and differing views on priorities as well as on company strategy. However, the perceived integrity of both partners and the CEO's ability, even if not fully satisfactory, had enabled the relationship to continue.

\section{The Chair's ability as a promoter of trust}

In the three dyads that belong in this group, the CEO was the major owner of the company and had been the first in the role as well as the key decision-maker in the appointment of the current Chair. The group includes dyads of various durations, as one dyad had worked together for less than two years and the other two dyads for more than five years. Even if both partners in all dyads narrated a relatively high level of trust right from the start of the relationship, the story lines were slightly different between the partners, as the CEO narrated a progressive, happily-ever-after story line with several examples of events that had increased their trust in the Chair, whereas the Chair mostly narrated a story line of stable trust in the relationship.

The decision of the CEO to invite the Chair to take up the position had largely been based on their perception of the Chair's ability. Specifically, the CEO had perceived the Chair's ability as complementary to her/his own, and as relevant to the challenges the company faced. Moreover, the CEO's initial perception of the Chair's potential benevolence had been affirmed when the Chair had agreed to take the position despite the fact that they were able to offer a level of compensation that was very low in proportion to the Chair's experience and competence. Actually, one of the Chairpersons did not take any compensation at all for the position, while another had invested in the company when she/he had started as Chair. 
The ability of the Chair to contribute continuously to the company's business and her/his readiness to take the time to support the CEO were highlighted by both partners, and the CEO's vulnerability in response to the Chairperson's actions was largely missing in this narration. Instead, the Chair emphasised that due to the CEO's major ownership of the company, the CEO's trust in the Chair was more relevant and crucial than vice versa. As one Chair expressed it: 'And as the CEO is the major owner in this company, the setting is such that I need to be trusted by the CEO, rather than vice versa, as is usually the case.'

The CEO spoke of many events and issues that had increased her/his trust in the Chair during the course of the relationship. These included the Chair's advice about company strategy and her/his help keeping the company to the agreed course of action, about arranging finance and ownership structures in the company, about negotiating and forming new customer relationships and agreements, about getting the CEO to act on some difficult personnel issues, as well as more personal support, for example during the CEO's divorce. As one CEO commented: 'All those things that (the Chair's first name) has brought along, have been extraordinarily good. I mean, not a single bad thing, in principle'. Moreover, the CEO highlighted the Chairperson's support in both the company's and her/his personal growth, and said it had significantly helped her/him to cope with the pressures she/he faced as an entrepreneur. A CEO described this as follows: 'When (the Chair's first name) comes here, you get the feeling that there's peace on earth. And the kind of analytical and calm manner she/he has - considering and questioning - is just great. (The Chair's first name) does not give answers. She/he asks the right questions.'

Rather than being protective of their autonomy, the CEOs in this group had mostly been delighted with any initiatives for contact that the Chair had made, and warmly welcomed all challenging and advice the Chair had given them. In fact, they said that they would be ready to take even more of that, but they understood that the Chair had only a limited amount of time for the role because of her/his other engagements.

The Chairpersons emphasised their ability to contribute to the company's business and to support the CEO, rather than control in the relationship. However, as there were also other owners in all these companies, the Chairpersons also said they had noted the need to consider other shareholders when making decisions. They also narrated that they had established a firm foundation for co-operation at the start of the relationship by working out basic questions with the CEO very thoroughly - why the company exists and what the owners want it to be in the 
long run - highlighting the importance of a common understanding of the mission and strategy of the company. Rather than specifically emphasising the importance to the development of trust of the CEO's ability, the Chairpersons said that the CEO needed to be honest and open with them, ready to listen to their advice and execute the chosen strategy. Moreover, they said that they would resign if they felt that they were unable to make a proper contribution, if distrust between the partners emerged for any reason, or if they strongly disagreed on a major matter. As one Chair concluded: 'Anyway, the starting point is that this company operates according to what the CEO wants.'

To sum up, in this group, trust was largely based on the ability of the Chair to contribute to the business and support the CEO, and the willingness of both partners to work together to develop the company.

\section{A summary of the results}

For the four groups, the following typology can be presented (Figure 1):

Figure 1. Summary of the results: key drivers and level of trust

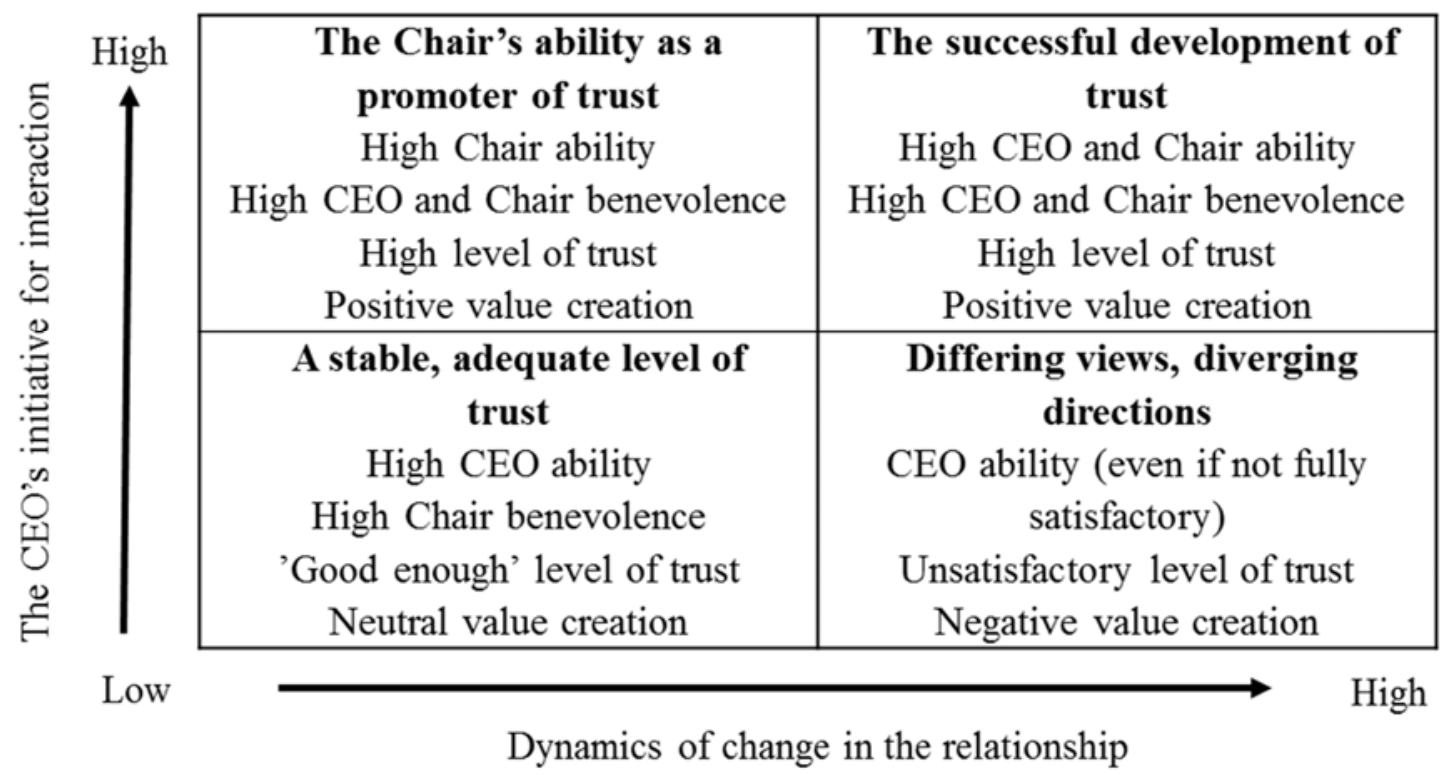

Note: In all the groups, the integrity of the dyadic partner was perceived as at least sufficient. The ability component in Figure 1 refers to companyspecific, rather than more general ability. 
In the groups in the upper boxes of Figure 1, the dyadic partners constructed active, largely CEO-initiated interaction that contributed to the Chair having a high level of companyspecific ability. In these groups, the dyadic partners spoke about a mutually satisfactory, hightrust relationship, which created value to the CEO and the company. This was achieved, for example, by the Chair's well-considered questions and new perspectives, and the additional insights and information provided by the Chair in the dyadic interaction. In addition, the dyadic partners narrated a co-created, shared view of company strategy as an outcome of their active co-operation.

In contrast, in the groups located in the lower boxes of Figure 1, interaction between the partners was infrequent, largely due to the failure of the CEO to take the initiative. Trust in the relationship and the company-specific ability of the Chair had not developed to a high level, and the relationship was not narrated as particularly creating value to the partners or the company; rather, the partners worked separately in their roles. Interestingly, the CEOs in the lower half of the figure said that the ability of the Chair to contribute to the business was not as good as it should have been. At the same time, they themselves had not contributed to the development of the Chairperson's company-specific ability by actively sharing information on company issues with them.

In the 'Differing views, diverging directions' group, the Chair perceived the ability of the CEO to be not fully satisfactory, while in the group 'The Chair's ability as a promoter of trust', CEO ability was not construed as being as pivotal for trust as in the other groups, maybe because the CEO's position was based on the ownership of the company rather than on ability. However, this is not to say that the Chair perceived the ability of the CEO as in any way unsatisfactory, but rather that the importance of the CEO's ability for trust was not emphasised in the same way as in the other groups.

\section{Discussion}

The key role and to a certain extent on-off nature of trust and the vulnerability (Mayer et al., 1995) of the CEO in particular were all underlined in the talk of nearly all respondents when referring to the inevitable end of the relationship, typically coming about by the Board's decision to dismiss the CEO, if trust were lost. We propose that the on-off nature of trust concerns the crucial line between trust and distrust and the consequent possibility of continuing the relationship, while the level of trust is more diverse and more open to change while the relationship exists. 
At the start of the relationship, there appears to be a baseline of trust rather than distrust (Lewicki et al., 2006). However, this propensity to trust (Mayer et al., 1995) may influenced by the similar cultural background of the partners (e.g. Lewicki et al., 2006) and the national context of the study, namely Finland, which is a high-trust society (e.g. Bjørnskov, 2007) with a low power distance culture (Hofstede, 1983). In a context of this kind, it may be that the partners act and expect each other to act as stewards, and this may contribute to a positive cycle of trust development rather than a negative development (Davis et al., 1997; Roberts and Stiles, 1999; Sundaramurthy and Lewis, 2003).

Our findings lead us to propose that in the CEO-Chair relationship, integrity (Mayer et al., 1995) is a necessity, rather than something that will develop trust further (Lapidot et al., 2007): it is important that the partners perceive each other as acting on the basis of a set of values that both partners find acceptable. However, it may be that even a very high level of integrity neither increases trust nor compensates for lack of ability or benevolence in the relationship (cf. Del Brio et al., 2013).

An agreement on company strategy, i.e. goal congruency (cf. Jensen and Meckling, 1976; Davis et al., 1997), was narrated by both partners as another important foundation for a trusting relationship. Such agreement could develop into a shared, co-created view of strategy as a result of the intensive interaction of the partners on emerging issues and challenges, and the possible responses to those challenges (Koskinen and Lämsä, 2016). This dynamic highlights the processual, reinforcing and cyclical nature of trust in the relationship: high-trust relationships are characterised by openness and continuous interaction (Huse et al., 2005; Roberts et al., 2005), whereas a lack of willingness to be vulnerable (Mayer et al., 1995) may lead to a lack of interaction and defensiveness over, for example, a chosen strategy, rather than co-created views on it (Sundaramurthy and Lewis, 2003).

\section{The meaning of ability and benevolence}

It is suggested that the meaning and perceptions of ability and benevolence (Mayer et al., 1995) of the dyadic partner are dynamic and evolving, reciprocally interlinked and to some extent complementary and context-dependent. It is also proposed that the specific 'contents' and significance of benevolence and ability are different for CEO and Chair. The ability of the CEO was narrated as being both necessary for trust and an important builder of trust. For the CEO to be perceived as trustworthy, the ability to execute strategic plans and to deliver the promised results is most important, even if this ability results in the strategic development and 
performance of the company rather than directly in any consequences for the CEO-Chair relationship (Serva and Fuller, 2004; Yakovleva et al., 2010). Moreover, when the ability of the $\mathrm{CEO}$ is perceived as being very high, this may compensate for a lower perception of CEO benevolence (cf. Del Brio et al., 2013). The CEO's benevolence is manifested in being open with the Chair beyond what must be told (Mayer et al., 1995; Lapidot et al., 2007).

As regards the CEO's perception of the Chairperson's trustworthiness, the Chairperson's benevolence in terms of allowing the CEO autonomy (Davis et al., 1997; Seppälä et al., 2011), rather than performing any particular action (cf. Mayer et al., 1995) was narrated as being most important. However, the willingness of the Chair to allow the CEO autonomy may largely depend on the Chairperson's perception of the CEO's ability (Del Brio et al., 2013). Particularly early on in the CEO's tenure, when there is not yet enough information about the CEO's ability to perform, the Chair may need to compensate for this uncertainty by more closely monitoring what the CEO does (Davis et al., 1997). The Chairperson's benevolence in the form of supporting the CEO is also considered to be meaningful for the development of trust to a higher level: by promoting the CEO's initiative for frequent interaction between the dyadic partners, it enhances the predictability of the actions of the other partner (Koskinen and Lämsä, 2016), results in less information asymmetry (Gabrielsson and Huse, 2002), and consequently further enables better support, such as advice and counsel (Zahra and Pearce, 1989), for the CEO as the Chairperson's company-specific ability increases. The balance of vulnerability of both partners and the reciprocal nature of trust in the CEO-Chair relationship is specifically highlighted here: the CEO must be willing to accept vulnerability to the Chair's actions when giving the Chair more information on company issues, and the CEO's openness is pivotal for the Chair to perform her/his duties. On the other hand, the CEO's perception of the Chair's benevolence may increase when the Chair is well enough informed to be able to interfere and for example impose certain decisions, but refrains from doing so (Fehr and List, 2004).

\section{The meaning of the order of entry into the relationship}

Our findings lead us to propose that the dynamics of trust development in the CEO-Chair relationship may be different depending on which of the partners is the first to start in her/his role. One reason for this may be that when the Chair is the first in the role, she/he will be in a key position in the recruitment process of the CEO, and both partners can make the decision and commitment to work together with the other partner. In particular, it is proposed that this 
process may enhance the perceptions of benevolence (Mayer et al., 1995) of both partners. In situations where the CEO is the first of the partners in her/his role, this process of 'mutual choice' does not take place. If, too, the CEO has been disappointed by the change of Chair, this may influence how the relationship with the new Chair forms (Ballinger et al., 2009). Other issues that may contribute to the possible difference are ability and information asymmetry: when the Chair is in position first and starts working with a new CEO, particularly when the CEO is recruited from outside the company, for a short period of time the Chair has more company-specific knowledge than the new CEO. When the CEO is the first of the partners in the role, the information asymmetry in her/his favour is considerable right from the start and she/he may have already proven her/his leadership in the role (Hambrick and Fukutomi, 1991; Shen, 2003), established a position of authority in the organisation (Cornforth and Macmillan, 2016), and be used to a high degree of autonomy. The CEO may be reluctant to jeopardise this autonomy by being more open with the Chair than she/he finds necessary. For the new Chair, on the other hand, getting information from the CEO is a very important factor in building the company-specific knowledge that is needed to really take charge in the role. However, our results show that something might happen, such as a conflict in the Boardroom, in which the Chair is able to show her/his ability and benevolence to support the CEO, and this can have a strong influence on the development of trust in the relationship because of the resulting increased reciprocal benevolence manifested in the openness of the CEO.

\section{The meaning of the CEO's or Chairperson's major ownership}

The nature of trust and the dynamics of trust development in the CEO-Chair relationship appear to be different if the CEO is a major owner of the company, i.e. when the CEO represents both the principal and the agent (Jensen and Meckling, 1976) in the relationship. In this kind of relationship, the CEO is less likely to be dismissed due to poor performance (e.g. Maury, 2006), and is less vulnerable to the actions of the Chair, as she/he can basically choose the Chair or at least strongly influence the appointment, as well as decide at any time to change the Chair. Consequently, there seems to be less concern about the autonomy of the (owner-)CEO and much more emphasis is given by both partners to the ability of the Chair to contribute to the business, increase the confidence of external stakeholders and complement and support the CEO (Huse and Zattoni, 2008). Moreover, the partners are able to evaluate the benevolence and ability of the other partner when negotiating over the Chairpersonship, and as discussed above, the willingness of both partners to agree to work together can be 
assumed to reciprocally increase initial perceptions of benevolence. This kind of relationship may therefore actually start at a higher level of trust than is normally the case.

On the other hand, trust development in relationships in which the Chair is a major owner appears to differ less from its development in relationships in which neither of the dyadic partners is a significant owner in the company. This may be due to the fact that the Chair always represents the principal, i.e. the owner, in the relationship, regardless of her/his personal ownership.

\section{Practical implications}

The practical implications of the study highlight the importance of efforts on both sides to build trust, and particularly continuous processes of open interaction initiated by the CEO once she/he has perceived that the Chair is trustworthy enough in terms of benevolence. Our results give support to the cyclical, self-fulfilling and reinforcing nature of trust (Davis et al., 1997; Roberts and Stiles, 1999; Sundaramurthy and Lewis, 2003). In line with Roberts and Stiles (1999), we highlight the pivotal importance of the start of the relationship, and in particular propose the importance of an open discussion at this stage on expectations and common rules in the relationship between the partners. Moreover, special attention should be paid to dyadic trust-building in situations in which a new Chair enters into a relationship with a long-standing, high-performing CEO.

The separation of the roles of CEO and Chair has not been found to improve company performance on its own (e.g. Krause et al., 2014). However, our findings suggest that the performance implications of CEO non-duality may be influenced by the level of trust in the CEO-Chair relationship. The level of trust in the CEO-Chair relationship is particularly important for value creation in the relationship, because in a high-trust relationship, the possibility of both partners making a contribution to the company is enhanced through knowledge sharing and learning in open interaction.

\section{Limitations and suggestions for further studies}

A severe limitation of this study is that the empirical data was generated in one country, Finland. As the development of trust relationships is influenced by the social-cultural context (Lämsä and Pucetaite, 2006; Wright and Ehnert, 2010), it would be valuable to conduct similar studies in other contexts, particularly in low-trust societies, and with dyads in which the partners come from different socio-cultural backgrounds. In particular, the propensity to 
trust (Mayer et al., 1995) of the CEO and Chair may be on a lower level in low-trust societies or where there is cultural dissimilarity, and therefore our findings concerning the start of the relationship above the zero level of trust may not apply. This, in turn, is likely to influence the early dynamics and make it more difficult to generate the positive, re-enforcing dynamic of trust development that applied to the majority of dyads in this study. In addition to socialcultural issues, the Companies Act, corporate governance codes and the guidelines they provide for these role-holders also differ from one country to another, which may influence the meaning and development of trust in the relationship across countries.

Another major limitation of this study is the attempt to study the development of trust based on interviews conducted at one point in time rather than on longitudinal data. This means that the issues and events were selected by the respondents at the time of the interview, and the narratives they told might have been influenced by the current level of trust in the relationship (Gergen and Gergen, 1988; Bruner, 1991; Polkinghorne, 1995). Due to this issue, and the relatively small body of research using longitudinal data in the areas of Board work and the CEO-Chair relationship (Stewart, 1991; Huse, 1998; Huse et al., 2005; Cornforth and Macmillan, 2016), and trust development (Serva et al., 2005; Ballinger et al., 2009; Colquitt et al., 2011), we suggest that the topic merits a longitudinal research setting. However, we find our narrative approach and the data generated by this study are valuable due to the qualitative, rich nature and dyadic setting of the study.

The dyadic setting also set limits, however, to how the data can be displayed. As the partners were guaranteed confidentiality in relation to their dyadic partner, certain restrictions apply especially to the citations used in the study report. For example, we as researchers were asked to not reveal some specific, sensitive issues that were described in the interviews, as they might be recognised by the other partner. On the other hand, it appeared that the fact that the respondents knew that their partner would be able to tell her/his side of the story to the same researcher may have reduced 'whitewashing'. Instead, the respondents wanted to explain their side of the story, and possibly also answer to the criticism they assumed the other partner might have raised in her/his interview.

An interesting area of further study would be the effects of order of entry and tenure on the relationship. In line with some other authors (Hambrick and Fukutomi, 1991; Shen, 2003; Huse, 2007; Cornforth and Macmillan, 2016), we propose that the relational dynamics 
develop differently depending on the tenure of the partners in the position, and may be influenced by the other partner's affective reactions to the turnover (Ballinger et al., 2009).

Loss of trust in the CEO-Chair relationship would merit research, as the respondents in this study said that in the case of lost trust, the relationship would likely end in the CEO's dismissal. Still, even if the antecedents of executive dismissal have received much research interest (see Hilger et al., 2013), studies examining the process leading to the loss of trust in this relationship are very rare.

\section{Conclusion}

It can be concluded that even if a sufficient amount of trust was narrated as being a prerequisite for the continuation of the CEO-Chair relationship, trust is dynamic and can take different levels during the course of the relationship, and it can develop in a cyclical, cumulative way.

In sum, the key reciprocal dynamics of interpersonal trust development in the CEO-Chair relationship appear to emerge around the CEO's ability to deliver the promised results, the Chair's willingness to allow the CEO autonomy and give support, open information-sharing largely initiated by the CEO, and the consequent company-specific ability of the Chair. The final results of this high-quality interaction are shared understandings of emerging changes, challenges and opportunities, and a shared view of the response to these challenges and opportunities in the form of company strategy.

\section{References}

Arvopaperimarkkinayhdistys ry (2010),"Suomen listayhtiöiden hallinnointikoodi (Corporate Governance)", available at: http://cgfinland.fi/files/2012/01/suomen-listayhtioidenhallinnointikoodi-cg2010.pdf. (accessed 17 December 2012).

Atkinson, S. (2004), "Senior management relationships and trust: an exploratory study", Journal of Managerial Psychology, Vol. 19 No. 6, pp. 571-587.

Bailey, B.C. and Peck, S.I. (2013), "Boardroom Strategic Decision-Making Style: Understanding the Antecedents", Corporate Governance: An International Review, Vol. 21 No. 2, pp. 131-146.

Ballinger, G.A., Schoorman, F.D. and Lehman, D.W. (2009), "Will you trust your new boss? The role of affective reactions to leadership succession", The Leadership Quarterly, Vol. 20 No. 2, pp. 219-232. 
Berger, P. and Luckmann, T. (1966), The social construction of knowledge: A treatise in the sociology of knowledge, Doubleday New York, NY.

Bjørnskov, C. (2007), "Determinants of generalized trust: A cross-country comparison", Public Choice, Vol. 130 No. 1-2, pp. 1-21.

Bruner, J. (1991), "The narrative construction of reality", Critical Inquiry, Vol. 18 No. 1, pp. $1-21$.

Colquitt, J.A., Scott, B.A. and LePine, J.A. (2007), "Trust, trustworthiness, and trust propensity: a meta-analytic test of their unique relationships with risk taking and job performance", Journal of Applied Psychology, Vol. 92 No. 4, 909-927.

Colquitt, J.A., LePine, J.A., Zapata, C.P. and Wild, R.E. (2011), "Trust in typical and highreliability contexts: Building and reacting to trust among firefighters", Academy of Management Journal, Vol. 54 No. 5, pp. 999-1015.

Cornforth, C. and Macmillan, R. (2016), "Evolution in Board Chair-CEO Relationships A Negotiated Order Perspective", Nonprofit and Voluntary Sector Quarterly, Vol. 45 No. 5, pp. 949-970.

Davis, J.H., Schoorman, F.D. and Donaldson, L. (1997), "Toward a stewardship theory of management", Academy of Management Review, Vol. 22 No. 1, pp. 20-47.

Del Brio, E.B., Yoshikawa, T., Connelly, C.E. and Tan, W.L. (2013), "The effects of CEO trustworthiness on directors' monitoring and resource provision", Journal of Business Ethics, Vol. 118 No. 1, pp. 155-169.

Eriksson, P. and Kovalainen, A. (2008), Qualitative Methods in Business Research, SAGE, London.

Fehr, E. and List, J.A. (2004), "The hidden costs and returns of incentives - trust and trustworthiness among CEOs", Journal of the European Economic Association, Vol. 2 No. 5, pp. 743-771.

Gabrielsson, J. and Huse, M. (2002), "The venture capitalist and the board of directors in SMEs: roles and processes", Venture Capital: An International Journal of Entrepreneurial Finance, Vol. 4 No. 2, pp. 125-146.

Gergen, K.J. and Gergen, M.M. (1988), "Narrative and the self as relationship", Advances in Experimental Social Psychology, Vol. 21 No. 1, pp. 17-56.

Gergen, M. and Gergen, K. (2006), "Narratives in action", Narrative Inquiry, Vol. 16 No. 1, pp. 112-121.

Hambrick, D.C. and Fukutomi, G.D. (1991), "The seasons of a CEO's tenure", Academy of Management Review, Vol. 16 No. 4, pp. 719-742.

Heikkinen, S., Lämsä, A.M. and Hiillos, M. (2014), "Narratives by women managers about spousal support for their careers", Scandinavian Journal of Management, Vol. 30 No. 1, pp. 27-39. 
Hilger, S., Mankel, S. and Richter, A. (2013), "The use and effectiveness of top executive dismissal”, The Leadership Quarterly, Vol. 24 No. 1, pp. 9-28.

Hofstede, G. (1983), "The cultural relativity of organizational practices and theories", Journal of International Business Studies, Vol. 14 No. 2, pp. 75-89.

Hooghiemstra, R. and Van Manen, J. (2004), “The Independence Paradox:(im) possibilities facing non-executive directors in The Netherlands", Corporate Governance: An International Review, Vol. 12 No. 3, pp. 314-324.

Huse, M. (1998), "Researching the dynamics of board-stakeholder relations", Long Range Planning, Vol. 31 No. 2, pp. 218-226.

Huse, M. (2007), Boards, governance and value creation, Cambridge University Press, Cambridge.

Huse, M., Minichilli, A., and Schøning, M. (2005), "Corporate Boards as Assets for Operating in the New Europe: The Value of Process-Oriented Boardroom Dynamics", Organizational Dynamics, Vol. 34 No. 3, pp. 285-297.

Huse, M. and Zattoni, A. (2008), "Trust, firm life cycle, and actual board behavior: Evidence from" one of the lads" in the board of three small firms", International Studies of Management \& Organization, Vol. 38 No. 3, pp. 71-97.

Jensen, M.C. and Meckling, W.H. (1976), "Agency Costs and the Theory of the Firm", Journal of Financial Economics, Vol. 3 No. 4, pp. 305-360.

Kakabadse, A., Kakabadse, N.K. and Barratt, R. (2006), "Chairman and chief executive officer (CEO): that sacred and secret relationship", Journal of Management Development, Vol. 25 No. 2, pp. 134-150.

Kakabadse, A.P., Kakabadse, N.K. and Knyght, R. (2010), "The chemistry factor in the Chairman/CEO relationship", European Management Journal, Vol. 28 No. 4, pp. 285-296.

Koskinen, S. and Lämsä, A.M. (2016), "The CEO-Chair relationship from a relational leadership perspective", Leadership \& Organization Development Journal, Vol. 37 No. 8, pp. $1135-1146$.

Krause, R., Semadeni, M. and Cannella, A.A. (2014), "CEO Duality: A Review and Research Agenda", Journal of Management, Vol. 40 No. 1, pp. 256-286.

Lämsä, A.M. and Pucetaite, R. (2006), "Development of organizational trust among employees from a contextual perspective", Business Ethics: A European Review, Vol. 15 No. 2, pp. 130-141.

Lapidot, Y., Kark, R. and Shamir, B. (2007), "The impact of situational vulnerability on the development and erosion of followers' trust in their leader", The Leadership Quarterly, Vol. 18, No. 1, pp. 16-34.

Lewicki, R. and Bunker, B.B. (1996), "Developing and maintaining trust in work relationships", in Kramer, R. and Tyler, T. (Eds.), Trust in organizations, Sage, Thousand Oaks, CA, pp. 114-139. 
Lewicki, R.J., Tomlinson, E.C. and Gillespie, N. (2006), "Models of interpersonal trust development: Theoretical approaches, empirical evidence, and future directions", Journal of Management, Vol. 32 No. 6, pp. 991-1022.

Maury, B. (2006), "Corporate performance, corporate governance and top executive turnover in Finland”, European Financial Management, Vol. 12 No. 2, pp. 221-248.

Mayer, R.C., Davis, J.H. and Schoorman, F.D. (1995), "An integrative model of organizational trust”, Academy of Management Review, Vol. 20 No. 3, pp. 709-734.

Nienaber, A.M., Romeike, P.D., Searle, R. and Schewe, G. (2015), "A qualitative metaanalysis of trust in supervisor-subordinate relationships", Journal of Managerial Psychology, Vol. 30 No. 5, pp. 507-534.

Osakeyhtiölaki 624 (2006), available at: http://www.finlex.fi/fi/laki/ajantasa/2006/20060624. (accessed 24 October 2016).

Pettigrew, A.M. (1992), “On studying managerial elites”, Strategic management journal, Vol. 13 No. S2, pp. 163-182.

Polkinghorne, D. (1988), Narrative knowing and the human sciences, State University of New York Press, Albany.

Polkinghorne, D.E. (1995), "Narrative configuration in qualitative analysis", International Journal of Qualitative Studies in Education, Vol. 8 No. 1, pp. 5-23.

Rhodes, C. and Brown, A.D. (2005), "Narrative, organizations and research", International Journal of Management Reviews, Vol. 7 No. 3, pp. 167-188.

Ricoeur, P. (1983), Time and narrative, Volume 1., The University of Chicago Press, Chicago.

Riessman, C.K. (2008), Narrative methods for the human sciences, Sage, Thousand Oaks, CA.

Roberts, J. (2002), "Building the complementary board. The work of the plc chairman", Long Range Planning, Vol. 35 No. 5, pp. 493-520.

Roberts, J. and Stiles, P. (1999), “The Relationship between Chairmen and Chief Executives: Competitive or Complementary Roles?”, Long Range Planning, Vol. 32 No. 1, pp. 36-48.

Roberts, J., McNulty, T. and Stiles, P. (2005), "Beyond agency conceptions of the work of the non-executive director: Creating accountability in the boardroom", British Journal of Management, Vol. 16 No. S1 pp. S5-S26.

Schoorman, F.D., Mayer, R.C. and Davis, J.H. (2007), "An integrative model of organizational trust: Past, present, and future", Academy of Management Review, Vol. 32 No. 2, pp. 344-354.

Seppälä, T., Lipponen, J., Pirttila-Backman, A.M. and Lipsanen, J. (2011), "Reciprocity of trust in the supervisor-subordinate relationship: The mediating role of autonomy and the sense of power", European Journal of Work and Organizational Psychology, Vol. 20 No. 6, pp. 755-778. 
Serva, M.A. and Fuller, M.A. (2004) "The effects of trustworthiness perceptions on the formation of initial trust: Implications for MIS student teams", Journal of Information Systems Education, Vol. 15 No. 4, pp. 383-395.

Serva, M.A., Fuller, M.A. and Mayer, R.C. (2005), "The reciprocal nature of trust: A longitudinal study of interacting teams", Journal of Organizational Behavior, Vol. 26 No. 6, pp. 625-648.

Shen, W. (2003), "The dynamics of the CEO-board relationship: An evolutionary perspective", Academy of Management Review, Vol. 28 No. 3, pp. 466-476.

Stewart, R. (1991), "Chairmen and chief executives: An exploration of their relationship", Journal of Management Studies, Vol. 28 No. 5, pp. 511-528.

Sundaramurthy, C. and Lewis, M. (2003), "Control and collaboration: Paradoxes of governance”, Academy of Management Review, Vol. 28 No. 3, pp. 397-415.

Uhl-Bien, M. (2006), "Relational leadership theory: Exploring the social processes of leadership and organizing", The Leadership Quarterly, Vol. 17 No. 6, pp. 654-676.

Westphal, J.D. (1999), "Collaboration in the boardroom: Behavioral and performance consequences of CEO-board social ties", Academy of Management Journal, Vol. 42 No. 1, pp. 7-24.

Whitener, E.M., Brodt, S.E., Korsgaard, M.A. and Werner, J.M. (1998), "Managers as initiators of trust: An exchange relationship framework for understanding managerial trustworthy behaviour", Academy of Management Review, Vol. 23 No. 3, pp. 513-530.

Wright, A. and Ehnert, I. (2010), "Making sense of trust across cultural contexts", in Saunders, M.N.K, Skinner D., Dietz, G., Gillespie, N. and Lewicki, R.J. (Eds.), Organizational Trust. A Cultural Perspective, Cambridge University Press, Cambridge, pp. 107-26.

Yakovleva, M., Reilly, R.R. and Werko, R. (2010), "Why do we trust? Moving beyond individual to dyadic perceptions", Journal of Applied Psychology, Vol. 95 No. 1, pp. 79-91.

Zahra, S.A. and Pearce, J.A. (1989), "Boards of directors and corporate financial performance: A review and integrative model", Journal of Management, Vol. 15 No. 2, pp. 291-334.

Zhang, P. (2013), "Power and trust in board-CEO relationships", Journal of Management \& Governance, Vol. 17 No. 3, pp. 745-765. 